\title{
Reading Habits, Language Learning Achievements and Principles for Deep Knowledge
}

\author{
I-Chin Nonie Chiang \\ Foreign Language Center, National Chengchi University, Taiwan
}

Copyright $(2016$ by authors, all rights reserved. Authors agree that this article remains permanently open access under the terms of the Creative Commons Attribution License 4.0 International License

\begin{abstract}
This paper intends to understand how the nine principles for deep knowledge (PDK) affect reading habits and language achievements by conducting a small-scale, experimental and statistical study. All 32 students participating in this study exhibit significant traits of PDK. The results suggest that inner-connection principle significantly correlates with academic performances. Deep-and-down and alternating principles significantly correlate with reading habits. Meanwhile, inner-connection principle effectively predicts academic performances and deep-and-low principle effectively forecasts reading habits. The mediating effect of PDK on language achievement is not statistically significant, possibly due to sample size, but nonetheless relevant and valuable to the prediction of reading habits. The development of reading habits for English-language materials takes a long time and good reading habits absolutely have profound impacts on the effectiveness of language learning. The integration of PDK characteristics into the establishment of reading habits can help build good habits in a more effective manner.
\end{abstract}

Keywords Language Learning, Language Achievement, Reading Habit, Habitual Domains, Principles for Deep Knowledge

\section{Introduction}

English has become a global language due to rapid internationalization and technological advancements. The efforts to acquire English proficiency have lasted for nearly half a century. The Taiwanese government has also been actively encouraging the learning of the English language with initiatives such as foreign language classes and examinations on English in elementary schools, a large variety of English proficiency tests, the minimum requirements in English capabilities for university admissions and graduations, "Mobile English Village" and reading habit promotion. Reading is a basic prerequisite for learning. We often read to acquire new knowledge but sometimes forget how to enjoy reading. As we age, the knowledge we are required to learn becomes tougher and we lose first the pleasure of reading and then often the habit of reading, without noticing it. Reading is a difficult endeavor by itself, particularly for the learners of a second or foreign language [1]. Generally speaking, well-read people have increased literacy and have improved verbal reasoning. They tend to score better on all kinds of tests [2-4] and report higher achievements in language learning $[5,6]$. There is a long list of factors associated with the often positive correlation between reading habits and learning achievements. This paper seeks to examine the role of deep knowledge theory in language learning, with a focus on the establishment of reading habits. Since inception years ago, deep knowledge theory [7] has been widely applied in different areas, such as academics [8], business [9], parent-child relationships [10], literature [11] and language learning [12-15].

The purpose of this study is to validate the influence of reading habits on language learning achievements by using principles for deep knowledge as the mediating variable and conducting statistical tests on the level of significance.

\section{Literature Review}

\subsection{Keys to Language Learning}

The two success factors in language learning are appropriate language inputs and sufficient language exposures. In general, linguists and educators all agree that language inputs play a pivotal role in language learning and the more, the merrier [1, p. 41, 16, 17]. This is one of the reasons why Taiwan and many other countries in the world incorporate foreign languages in the curricula of elementary schools. Starting early saves the number of total hours needed to acquire a foreign language [1, p.22]. Literature suggests that people who excel in foreign language learning spend more hours and start early at young age. This explains the emergence of immersion programs in different countries since the 1960s [18-24]. In Taiwan, English is still 
taught as a foreign language (FFL), and not as a second language (ESL). Immersion programs are only available in a number of select, experimental elementary and junior high schools. Most of the time, schools have to follow the curricula and learning outcomes required by the Ministry of Education, and all the teaching is limited to classrooms. This restriction is particularly an obstacle to foreign language learning because it limits the volume and the variety of language inputs. Chomsky [25] believes that only with primary linguistic data (PLD), the data children are exposed to and use in attaining their native grammars, can the learning mechanism for languages be triggered. Therefore, it is necessary to introduce extra-curricular inputs in order to reach the quantity required for language acquisition (in contrast with language learning, [26]) by empowering students to become autonomous learners who are able to pay attention to language inputs outside the classroom and create their own learning environment similar to immersion teaching. In Taiwan, the extra-curricular inputs most learners have are cram schools, whose offerings are no different from classrooms. The language inputs provided by cram schools are also mostly "learned" knowledge, not "acquired" knowledge. Krashen $[16,27]$ argues that knowledge acquisition only occurs with high motivations or with low anxiety (cf. Affective Filter, [16]). He started to promote free voluntary reading (FVR) in order to create a quasi-native scenario that is different from school teaching and an extra-curricular environment conducive to the enhancement of learning motivations and the mitigation of anxiety levels.

\subsection{Reading and Learning Achievements}

Whilst the research in language learning often distinguishes the acquisition of languages in natural environment and the learning of languages at classrooms, it does not mean language acquisition never occurs in the teaching scenario or vice versa. In fact, many studies contend that those who can learn in both methods achieve the best results [17, 27, 28]. Mahadeo [17], after investigating the relationship between exposure and both oral and written performance of 240 secondary students, concludes that limited extra-curricular input could influence learners' L2 proficiency negatively. In contrast, more proficient learners often benefit from after-class resources, e.g. reading for pleasure, or social interaction. Among all autonomous learning activities, the author believes that reading English-language novels is a more accessible method. Book reading does not require computer equipment or skills. It is readily available and can provide the English language inputs required by learners. Different from drills such as listening practice, novel reading allows different paces, repetitions or pauses for thinking. Meanwhile, studies indicate that over $83 \%$ learners are of the visual variety [29], so reading makes it easier for learners to observe the changes of tenses in the English language [1, p.42-43].
Among all the reading methods, FVR is the most suitable one to provide the experience necessary to encourage reading in English. FVR means reading out of a desire to read. It does not require writing a report or answering questions. There is no need to struggle through a book if you don't like it. FVR encourages students to read in English in the low-anxiety and input-rich scenario. Reading becomes fun and more likely develops into a habit. Krashen $[4,30]$ summarizes and compares a large number of studies on FVR and traditional teaching. Although the behavior of the students is no different under the FVR learning or traditional teaching, FVR adds pleasure to reading, and the affected learning aspects include comprehension, vocabulary, grammar, speaking, listening and writing. Krashen emphasizes that the longer FVR is implemented, the more promising the positive effects will become. Mason [5] reviews a series of studies, including quantitative experiments and case studies, to prove that free reading does more than change the reading attitude of students [31]. It is an efficient learning method [32], able to prepare students for tests [33, 34]. In sum, FVR is critical to language learning but often ignored.

\subsection{University Students' Current Habit in English-Language Novel Reading}

According to a study by Chiang [35] on 143 university students in Taiwan, the students are generally exposed to very limited English outside classrooms and do not own many extracurricular English-language books. Nearly half of the surveyed students show no interest in joining after-class reading groups or much desire to read in English. This indicates a lack of reading habit and an insufficiency of extra-curricular English inputs. Whilst the students do not hold a negative attitude toward English-language learning, they are not necessarily enthusiastic about it. The result is a lack of pursuit for spontaneous reading in English or exposure to the English language. In fact, there is a huge gap between their intention and behavior. Students show a high motivation, but spend little time reading. There is a discrepancy between their expected and actual reading hours. Yamashita [36] suggests that the absence of a negative attitude does not equal a positive attitude. It is also unlikely to entice students to read in English. The author believes that even university students rely on the arrangement and guidance from teachers to gradually learn to take pleasure in reading and hence to develop the habit of reading. As Mason [5, p.1] says, “...pleasurable reading could change reluctant EFL students to willing-to read students at the university level in Japan." In a nutshell, it is an imperative for English teachers in universities to utilize FVR to introduce changes in students.

Moreover, reading habits are important to language learning. The post-reading tests conducted by Waring and Takakei [37] indicate that vocabulary buildup is both distributed and incremental. In other words, the learning result is the best if new words appear in a distribution or 
interval. Therefore, distributed practices (spread out over time and a large number of short sessions) work out better than concentrated practices (crammed into one long session). A reading habit can achieve all these results, as preferred reading is done in multiple short time spans over time, rather than few long sessions.

\subsection{Principles for Deep Knowledge (PDK)}

Extracurricular reading is often a challenging strategic decision, because it is voluntary and without binding requirements. Thus, it is often sacrificed. Students usually give up reading for other activities [38, 39] and hence cannot develop a reading habit. It might be possible to apply other learning theories in conjunction with guidance from teachers to enhance the motivations of students to pursue extracurricular reading. Motivations trigger behavior, i.e. the time engaged in reading. The principles for deep knowledge [7, 40], i.e., the nine deep knowledge principles in the habitual domain, may be a good example.

According to the habitual domain (HD) theory, memories, concepts, behaviours and reactions gradually become stable over time and stay in a fixed range. This range is the habitual domain [7, 41]. A habitual domain consists of four elements: (1) the potential domain (PD) - the collection of ideas and thoughts that can potentially be activated, or the aggregation of all the power grids in our mind; (2) the actual domain $(\mathrm{AD})$ - the set of ideas and thoughts currently dominating our attention, contributing the greatest influence on us; (3) the activation probabilities (AP) - the probabilities of individual power grids grasping our attention; (4) the reachable domain (RD) - the extension of ideas and thoughts triggered by the actual operations of these ideas and thoughts. The habitual theory posits that habits are fixated in a range unless major events occur or contrived efforts are made to expand the habitual domain [42]. Therefore, we should stay alert by understanding and extending our habitual domains, in order to avoid the constraints of our own habits without realizing it.

HD theory sees the 'circuit patters' in the brain as the key to change. The more these circuit patterns are exercised, the more strengthened they become, the more likely we will be influenced by them when we make decisions, just like the so-called 'intuitive decisions' [7, p.72]. Similar to our brain cells, circuit patterns can be fortified with constant access, thought training and elaborative encoding, which will in turn expand the HDs. Constant access to old knowledge and update knowledge means to exercise circuit patterns. In language learning, new knowledge is often based on the old one; therefore, if the old and new knowledge can be connected easily, the learning efficiency should increase. When a child learns the mother tongue, s/he tests newly learned rules and reinforces positively or negatively the results to the memory and upgrade the information. When we are used to this, we change and expand our HDs. Chiang $[7, p .49]$ used the following figure to illustrate the similarity between the HD elements and human memory system. Stronger circuit patterns can increase Activation Probability, i.e., the ability to access and store information; as a result, stronger circuit patterns should enhance the efficiency of language learning.

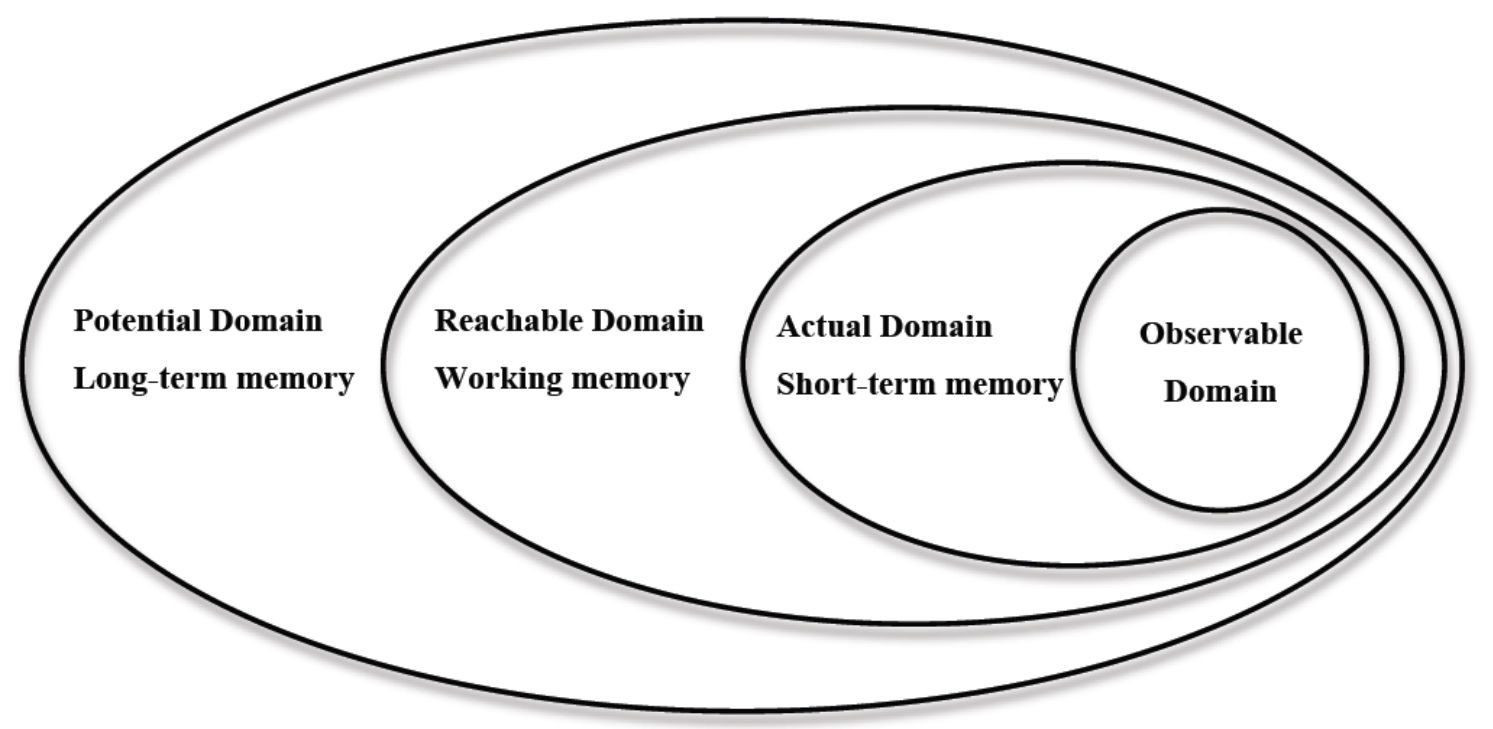

Figure 1. Four elements of HD and memory types 
The principles of deep knowledge are means of extending the boundaries of the habitual domain. Changes in ideas can lead to changes in actions. These principles help to uncover more and better ideas so as to effectively resolve problems [40]. There are a total of nine principles for deep knowledge: cracking and ripping principle; alternating principle; contrasting and complementing principle; void principle; inner-connection principle; revolving and cycling principle; changing and transforming principle; deep and down principle; contradiction principle. The deep knowledge principles allow a systematic approach to gauging the overall habitual domain of ours and others by observing the actual domain. This expands our own habitual domains and helps us to effectively grasp and handle problems [7]. Below is a detailed description of the nine deep knowledge principles [40] and the implementation in novel reading [41].

1. Deep and down principle: There are two meanings embedded within this principle: (1) To liberate desires and reduce stress levels so that the weaker power grids may attract our attention; (2) keep a humble attitude to absorb more and better ideas and expand the habitual domains. For instance, readers can often understand things that are difficult or things they have not experienced, like death, through stories to decrease the level of seriousness and learning stress.

2. Alternating principle: Sometimes it is necessary to set aside presumptions, hypotheses or prejudices in order to come up with a myriad of new and inspiring ideas. Novels often adopt different points of view in description, and this shows a reader different viewpoints and widens one's horizon.

3. Contrasting and complementing principle: A clear picture on both sides of the story and a sobering analysis on contracting and complementary characteristics can push the envelope of the habitual domains and spark new thoughts or creative concepts. While feeling surprised at the content, a readers is already experiencing HD expansion.

4. Revolving and cycling principle: The universe is constantly revolving in cycles. The leverage of this fundamental law helps to expand the actual domains and gain foresights. A book without unexpected plot is dull and is unlikely to bring reading satisfaction. Therefore, readers should choose books wisely, i.e. books that are interesting with a little twist or mystery to maintain reading motivation and build up reading habit.

5. Inner-connection principle: It is necessary to enable powerful connectivity and the more, the merrier. This allows more rapid and more effective use of our habitual domains and assists in the effective resolutions to problems. Emotions can bridge and connect knowledge and experience easily, so choosing a book with characters we can empathize and understand. This way, we can also connect the novel and real life better.

6. Changing and transforming principle: This involves going with the flows when it comes to changes in our own habitual domains or seeking to predict such changes. Each and every change poses a challenge to our limitations and pushes our ability to resolve problems with our habitual domains. Every reading is expanding HDs. However, we can challenge ourselves by putting down our own versions of stories in words or stories of our own.

7. Contradiction principle: This is an effective method to develop analytical and critical thinking skills. If a counterexample can be found, it is necessary to modify the conclusion so as to ensure the robustness of the judgment. A reader can write down his/her agreement and disagreement with the author's ideas and try to explain the differences. For example, the differences of the opinions or actions could be due to the differences in time and culture.

8. Cracking and ripping principle: Habitual domains consist of a large number of microsystems, which may conflict with each other and cause cracks. This is often the source of problems, which we should take heed and seek improvements. This is the only way to trigger changes to the habitual domains and hence strength the habitual domains. Readers can try to find out the conflicts of the story, think of possible solutions, predict the plots, and then gradually solve the problem while reading.

9. Void principle: It is necessary to empty our own habitual domain so that the domain can keep expanding. New knowledge can only enter our habitual domain if we let go of the constraints of existing thoughts. Therefore, we should learn to share our thoughts and learn from professional critiques to develop our knowledge.

Chiang [12] indicates that students with strong learning outcomes exhibit these nine deep knowledge principles, evidencing a close relationship between learning outcomes and deep knowledge principles. It is hence possible to integrate deep knowledge principles into reading plans so as to encourage the enthusiasm in reading and the formation of a reading habit. For example, the choice of interesting reading materials and subject matters can enhance the interest level in reading (changing and transforming principle). A wide selection of reading materials and the application of deep and down principle can reduce anxiety. The choice of reading materials is based on the interest level of students, not of the teachers (alternating principle). Repetition of the same books or emphasis on similar topics or the same author can step up the frequency of reading and highlight the relations between reading materials (inner-connection principle). These are all feasible strategies [13]. The only way to develop habits is via practices. In theory, the expansion of habitual domains helps us to change our choices. The practice through deep knowledge principles can reinforce behavior into habits.

In sum, this paper seeks to explore the relationship between reading habits, deep knowledge and learning achievements. The purpose is to explore whether reading habits influence learning achievements with deep knowledge principles as the mediating factor. 


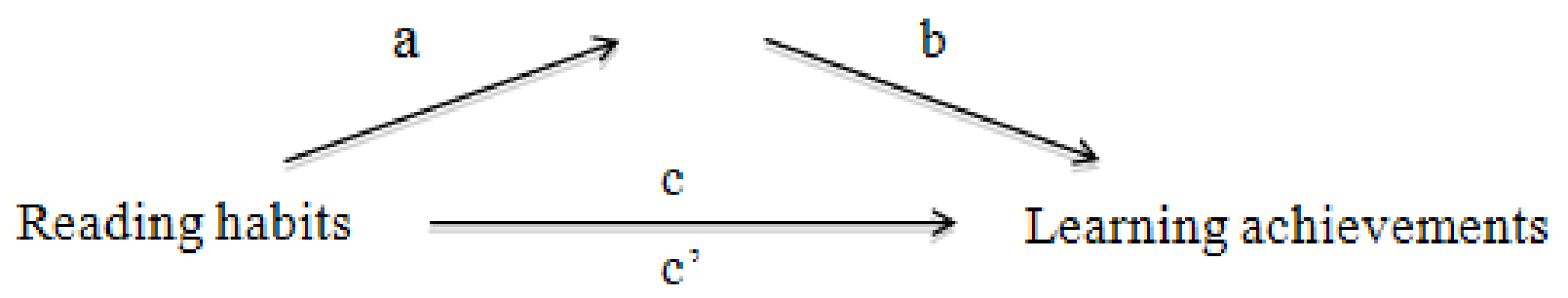

Figure 2. Relationship among Variables

\subsection{Objectives}

Expansion of habitual domains is a prerequisite for language learning. In other words, principles for deep knowledge are required traits for learning [12, 13]. This paper uses the measurement for deep knowledge principles developed by Chiang [12] and Chiang [13] to explore the relationship between reading habits, deep knowledge and learning achievements for university students. Reading habits are the independent variables and learning achievements are the dependent variables, as the impact of deep knowledge (Figure 2). The symbol "a" denotes the influence of reading habits (hours and frequencies) on deep knowledge, "b" the influence of deep knowledge on learning achievements, "c" the relationship between reading habits and learning achievements without the presence of deep knowledge as a variable, "c"" the (indirect) influence of deep knowledge on reading habits. In other words, this analysis examines reading habits by referring to the statistical significance of $c$ ' in order to validate the influence of deep knowledge on learning achievements.

\section{Methods}

\subsection{Subjects}

The sample was chosen by simple random selection from a state university in northern Taiwan. A total of 32 students $(n=32)$ taking an advanced English course participated in the study. Eleven of these were male, and 21 were female. None of the 32 participants had taken any classes related to habitual domains and they are not familiar with the nine principles of deep knowledge. They answered the questionnaire based on their own experience. Before the survey, the author made sure all the students were fully aware of the research purposes. They signed a consent form before taking part in the questionnaire survey and provided their academic reports of the semester as the research materials.

\subsection{Questionnaire}

The measurement contains two sections, reading habits and deep knowledge learning behaviour, as described below.

(1) Reading habits: The purpose of this section is to collate data concerning the hours and frequencies of reading. The questions were designed by the author and two experienced teachers in English, based on experience of teaching English in university. There are a total of 5 questions, as follows:

1. How many hours of extracurricular English reading do I have each week? $(1=30$ minutes; $2=30-60$ minutes; $3=60-90$ minutes; $4=90-120$ minutes; $5=120$ minutes and more)

2. How many times do I pick up extracurricular English reading materials each week? $(1=0$ time; 2 $=1-2$ times; $3=3-4$ times; $4=5-6$ times; $5=$ every day)

3. How many hours each week do I think I should spend on developing a habit of reading English-language materials outside classes? $(1=1-$ 3 hours; $2=4-5$ hours; $3=6-7$ hours; $4=8-9$ hours; $5=10$ hours or more)

4. How many extracurricular English books (i.e. non-textbooks $)$ do I have? $(1=1-5$ books; $2=6-$ 10 books; $3=11-15$ books; $4=16-20$ books; $5=$ 20 books or more)

5. How willing am I to participate in study groups for extracurricular English reading? (from 1 to 5, with 5 indicating the highest interest)

(2) Principles for deep knowledge: This paper refers to the measurement for nine principles for deep knowledge developed by Chiang [12] and sources a total of 30 questions on individual knowledge. Questions D1-D4 are on deep and down principle, D5-D7 on alternating principle, D8-D10 on contrasting and complementing principle, D11-D13 on revolving and cycling principle, D14-D17 on inner-connection principle, D18-D20 on changing and transforming principle, D21-D23 on contradiction principle; D24-26 on cracking and ripping principle, D27-30 on void principle. Questions D1, D8, D10, D12, D14, D16, D21, D22, D23 and D26 are inverse items. In Chiang's study, the internal consistency for the measurement, Cronbach's alpha value, is .82 .

\subsection{Learning Achievements}

With the consent from participating students, this paper refers to their end-of-semester academic reports as learning achievements. Overall learning achievement was indicated by five points of students' grade point average, 5 for a score of 90 and above, 4 for a score between 80 and 89,3 for a 
score between 70 and 79, 2 for a score between 60 and 69,1 for a score below 60. The assessment for this semester contains seven components: $10 \%$ for attendance, $10 \%$ for classroom debates; $5 \%$ for data inquiries after classes; $15 \%$ for discussions with teaching assistants, $15 \%$ for reports on novel reading; $30 \%$ for reports on weekly extracurricular reading, $15 \%$ for oral presentations at the end of the semester. The curriculum focuses on extracurricular reading and classroom involvements. Among which $50 \%$ of total scoring is related to reading, and $40 \%$ is related to verbal expressions.

\subsection{Data Collection and Statistical Techniques}

The questionnaire data collection was done in December 2012. The research purposes are to explore the potential characteristics of deep knowledge exhibited by the students not exposed to the theory of deep knowledge and to examine the influence of these characteristics on learning achievements. This paper gathers questionnaire data before the end of the semester and uses the end-of-semester results of the participating students as learning achievements.

To examine whether deep knowledge affects the relationship between learning habits and learning achievements, this paper employs SPSS (packaged software) to (1) calculate Pearson's product-moment correlation coefficient to validate the correlations between all variables; (2) to conduct a mediation analysis based on regressions, so as to test the variable relationships depicted in Figure 2 [44, 45]. To verify whether deep knowledge principles affect the relationship between reading habits and learning achievements, this paper refers to the mediation analysis to examine all the paths in Figure 2 - Relationships among Variables. The statistical significance of c' in Figure 2 is referred to in the exploration of the influence of reading habits (independent variable) on learning achievements (dependent variable) via deep knowledge (mediating value). This analysis uses the original model as the basis and applies bootstrapping procedures to plot the paths repeatedly with research data. The original model is then modified into the pattern closest to the sample distribution of the research data in order to derive the confidence interval of the influence. If deep knowledge serves as a mediating value and the resulting learning achievements do not include " 0 ", the influence of the mediating value can be deemed as statistical significant. The advantage of this approach is to avoid the erroneous assumption due to the parameter (c') estimate of path for the mediating value (principles for deep knowledge); (3) conduct multiple regressions to validate the predictive power of nine deep knowledge principles on language learning achievements and reading habits.

\section{Results}

\subsection{Reliability and Descriptive Statistical Analysis}

This paper conducts internal consistency tests. The coefficient is high for deep knowledge principles $(\alpha=.88)$ and satisfactory for reading habits $(\alpha=.70)$. A total of 32 students participated in the study (with 11 males and 21 females), including 3 freshmen, 12 sophomores, 10 juniors and 4 seniors. The majority of the participants spend 30 minutes reading in English after classes each week $(n=10)$ and only 4 spend more than 120 minutes per week. Interestingly, students "believe" they spend an average of 4.06 hours developing a habit of reading in English after classes each week ( $\mathrm{SD}=2.88)$, but the reality is that they don't pick up extracurricular English reading materials much after school. In fact, 7 students have zero exposure to extracurricular reading and 19 choose to spend 1-2 hours per week on extracurricular reading in English. On average, each student owns 6 extracurricular English books (SD = 7.20). There are 4 students who have none, 3 students who indicate that they have 1 book, 6 students who have 2 books, 5 students who have 3 books. This group adds to 18 students $(56.3 \%)$, in contrast with the students who have 10 books or more $(n=9,28.1 \%)$. It is worth noting that students in general are not interested in after-class English reading groups $(\mathrm{M}=2.91, \mathrm{SD}=1.25)$.

The scale is measured in 5 points, with a high point indicating greater deep knowledge. The average point of 3.5 is the cut-off point. In other words, deep knowledge principles are indicated with a point of at least 3.5. The average point for all the participants is above 3.5 , suggesting that they possess these learning attitudes. Among the nine principles, alternating principle reports the highest average of $3.99(\mathrm{SD}=.58)$, followed by changing and transforming principle $(\mathrm{M}=3.95, \mathrm{SD}=.53)$, inner-connection principle $(\mathrm{M}=3.92, \mathrm{SD}=.37)$, deep and down principle $(\mathrm{M}=3.88, \mathrm{SD}=.50)$, contradiction principle $(\mathrm{M}=3.86, \mathrm{SD}=.71)$, cracking and ripping $(\mathrm{M}=$ $3.85, \mathrm{SD}=.65)$, void principle $(\mathrm{M}=3.84, \mathrm{SD}=.39)$, revolving and cycling principle $(\mathrm{M}=3.69, \mathrm{SD}=.64)$, contrasting and complementing principle $(\mathrm{M}=3.68$, SD $=.46)$. 


\subsection{Correlation}

Table 1 shows the test results on Pearson's product-moment correlation coefficients. The research finding suggests a correlation between inner-connection principle and learning achievements $(r=.46, p<.05)$, between deep and down principle $(r=.41, p<.05)$ and reading habits and between alternating principle $(r=.42, p$ $<.05$ ) and reading habits. Meanwhile, there are also significant correlations between the nine variables of deep knowledge.

\subsection{Mediating Value}

This paper employs the add-on SPSS software (Preacher and Hayes, 2008, Multiple Mediation INDIRECT) to analyze mediating values, by referring reading habits as the independent variables, academic results as dependent variables and deep knowledge as the mediating variables. The results suggest no statistical significance for path c' (Table 2). This may be due to a small sample size, one of the research restrictions, which will be discussed in Section 5.

Table 1. Descriptive Statistics and Correlations

\begin{tabular}{|c|c|c|c|c|c|c|c|c|c|c|c|c|c|c|}
\hline Variable & $\mathrm{N}$ & M & $\mathrm{SD}$ & $\alpha$ & 3 & 9 & 10 & 11 & 12 & 13 & 14 & 15 & 16 & 17 \\
\hline 1. Male & 11 & & & & & & & & & & & & & \\
\hline 2. Female & 21 & & & & & & & & & & & & & \\
\hline 3. Grades & & 4.00 & 0.80 & & & & & & & & & & & \\
\hline $\begin{array}{l}\text { 4. Reading habit } 1 \\
\text { Habit } 1\end{array}$ & & 2.47 & 1.37 & & & & & & & & & & & \\
\hline 5. Reading habit 2 & & 2.06 & 0.88 & & & & & & & & & & & \\
\hline 6. Reading habit 3 & & 1.78 & 1.07 & & & & & & & & & & & \\
\hline 7. Reading habit 4 & & 1.59 & 1.13 & & & & & & & & & & & \\
\hline 8. Reading habit 5 & & 2.91 & 1.25 & & & & & & & & & & & \\
\hline 9. Reading habit & & 2.16 & 0.81 & .70 & .21 & & & & & & & & & \\
\hline 10. P1 & & 3.88 & 0.50 & & -.26 & $.41^{*}$ & & & & & & & & \\
\hline 11. P2 & & 3.99 & 0.58 & & -.02 & $.42 *$ & $.45^{* *}$ & & & & & & & \\
\hline 12. P3 & & 3.68 & 0.46 & & -.23 & -.18 & .32 & -.01 & & & & & & \\
\hline 13. P4 & & 3.69 & 0.64 & & .00 & .10 & $.44 *$ & $.52 * *$ & $.38 *$ & & & & & \\
\hline 14. P5 & & 3.92 & 0.37 & & $.46^{*}$ & -.03 & .09 & .22 & $.45^{* *}$ & .32 & & & & \\
\hline 15. P6 & & 3.95 & 0.53 & & -.30 & .07 & $.53 * *$ & $.70 * *$ & .25 & $.53 * *$ & .34 & & & \\
\hline 16. P7 & & 3.86 & 0.71 & & .13 & -.17 & .20 & .29 & $.40^{*}$ & $.40^{*}$ & $.49 * *$ & $.40 *$ & & \\
\hline 17. P8 & & 3.85 & 0.65 & & -.29 & .21 & $.58^{* *}$ & $.67^{* *}$ & $.53^{* *}$ & $.53^{* *}$ & .33 & $.56^{* *}$ & $.49^{* *}$ & \\
\hline 18. P9 & & 3.84 & 0.39 & & -.05 & .05 & .05 & .15 & $.48^{* *}$ & $.48^{* *}$ & .33 & .10 & .21 & $.51^{* *}$ \\
\hline 19. PDK & & 3.85 & 0.37 & .88 & & & & & & & & & & \\
\hline
\end{tabular}

Note: P1. Deep and Down. P2. Alternating. P3. Contrasting and Complementing. P4. Revolving and Cycling. P5. Inner-Connection. P6. Changing and Transforming. P7. Contradiction. P8. Cracking and Ripping. P9. Void.

$* p<.05$ (one tail); $* * p<.01$ (two tails)

Table 2. Mediating Values of Deep Knowledge Principles That Influence Reading Habits and Learning Achievements

\begin{tabular}{|c|c|c|c|c|c|c|c|c|c|c|c|c|}
\hline & & \multicolumn{2}{|c|}{ Path a } & \multicolumn{2}{|c|}{ Path b } & \multicolumn{2}{|c|}{ Path c } & \multicolumn{2}{|c|}{ Path c' } & \multirow{2}{*}{$\begin{array}{c}\mathrm{IE} \\
\beta\end{array}$} & \multicolumn{2}{|c|}{$95 \% \mathrm{CI}$} \\
\hline & & $\beta$ & $\mathrm{p}$ & $\beta$ & $\mathrm{p}$ & $\beta$ & $\mathrm{p}$ & $\beta$ & $\mathrm{p}$ & & Lower & Upper \\
\hline \multirow[t]{8}{*}{ Reading habits } & $\mathrm{P} 1$ & .26 & .02 & -.53 & .10 & .02 & .91 & .16 & .43 & -.12 & -.32 & .02 \\
\hline & P3 & -.11 & .33 & -.41 & .21 & .02 & .91 & -.02 & .91 & -.00 & -.11 & .32 \\
\hline & P4 & .08 & .58 & -.00 & .99 & .02 & .91 & .02 & .91 & .01 & -.09 & .06 \\
\hline & P6 & .05 & .69 & -.47 & .09 & .02 & .91 & .04 & .81 & -.01 & -.24 & .13 \\
\hline & $\mathrm{P} 7$ & -.16 & .34 & .16 & .46 & .02 & .91 & .05 & .81 & -.03 & -.21 & .13 \\
\hline & P8 & .17 & .25 & -.38 & .10 & .02 & .91 & .09 & .64 & -.06 & -.34 & .02 \\
\hline & P9 & .02 & .79 & -.11 & .78 & .02 & .91 & .02 & .90 & .02 & -.17 & .04 \\
\hline & total & .06 & .49 & -.31 & .45 & .02 & .91 & .04 & .84 & -.01 & -.26 & .04 \\
\hline
\end{tabular}




\subsection{Multiple Regressions}

Table 3 presents the results of the stepwise multiple regression analysis on predictive power. Among the nine deep knowledge principles, only inner-connection principle has significant predictive power over academic results $\left(\mathrm{R}^{2}\right.$ $=.23, \beta=-.51, p<.05)$ and only deep and down principle reports significant predictive power on reading habits $\left(\mathrm{R}^{2}\right.$ $=.28, \beta=.53, p<.05)$.

Table 3. Multiple Regression Analysis

\begin{tabular}{cccc}
\hline $\begin{array}{c}\text { Dependent } \\
\text { variable }\end{array}$ & $R^{2}$ & ANOVA & Predicting variable and beta \\
\hline $\begin{array}{c}\text { Academic } \\
\text { results }\end{array}$ & 0.23 & $7.53^{*}$ & $\begin{array}{c}\text { Inner-connection principle } \\
\left(\beta=-.51^{*}\right)\end{array}$ \\
Reading habit & 0.28 & $5.64^{*}$ & $\begin{array}{c}\text { Deep and down principle } \\
\left(\beta=.53^{*}\right)\end{array}$ \\
\hline
\end{tabular}

Note: ${ }^{*} p<.05$.

\section{Discussion}

This paper intends to conduct quantitative statistical analysis to prove that deep knowledge can influence reading habits and boost learning achievements in English language study. However, the results are not conclusive. The mean score of the 32 students participated is $84.21(\mathrm{SD}=9.22)$. Only 4 of them posted a score lower than 75 . Most of their scores are in the range of 77-99, with 7 of them earning a score above 94. The results suggest that their English proficiency is fairly satisfactory. In addition, the mean points for the nine deep knowledge principles are all above the cut-off point of 3.5, indicating that they all possess these learning attributes and deep knowledge $(\mathrm{M}=3.86$, SD $=.42$ ). The small sample size makes it difficult to observe the influence of reading habits on learning achievements with deep knowledge as the mediating variable. This is a typical problem associated with a small sample size. Thus, it is suggested that follow-up studies be undertaken, to expand sample size and to more convincingly validate the significance of the research model.

This paper notices a gap between the perception and the reality concerning the reading habits of the surveyed students. This is similar with the research finding of Chiang [35]. Students do not behave as they think they should. Also, they are not motivated to join reading groups after class. In other words, they have not formed a habit of reading in English in their spare time. In theory, the time spent on extracurricular reading in English and the volume of English materials read should be one of the major determinants of language learning achievements. Further studies are suggested to survey the minimum hours and the minimum quantity required for extracurricular reading to influence learning effectiveness [1], and explore the ways with which principles for deep knowledge can effectively boost English learning outcomes. Whilst as the reading habit measurement developed by this paper boasts the expert validity and acceptable internal consistency and reliability, future studies are recommended to test on the construct validity.

According to the test results on Pearson's product-moment correlation coefficients shown in Table 1, inner-connection principle and academic reports are correlated $(r=.46, p<.05)$. Chiang [12] also indicates that inner-connection principle demonstrates the highest average among all the nine deep knowledge principles. This suggests a high correlation between inner-connection principle and learning achievements and can be explained by how our brains work in the light of modern theories [13]. When we connect our thoughts and learning activities by associating with old and new knowledge and personal experiences, we respond faster and create deeper impressions. Those who have high learning achievements tend to be familiar with the English language or spend more hours learning and hence they are capable of making associations, an attribute called inner-connections.

Moreover, the research suggests that deep and down principle $(r=.41, p<.05)$ and alternating principle $(r=.42$, $p<.05)$ are significantly correlated with reading habits. Deep and down principle emphasizes let-go and destress. Only big and strong power grids can attract attention at high stress levels. If the stress level is tuned down, weaker power grids (which contain a variety of subject matters and thoughts) can also receive attention [7]. The reading pleasure we advocate as part of the after-class reading program is consistent with deep and down principle. Krashen $[16,26]$ believes that acquiring only occurs with high motivations and low stress levels. Only when we can enjoy reading are we able to develop the motivation and habit of reading and indulge ourselves in the world created by books. The alternating principle states that new ideas are generated when the relevant presumptions and presuppositions are removed, replaced or combined. Learners should not think reading in English is a daunting task, or assume that they have to read the books suitable for their ages or knowledge levels. They can try easy and simple books for children or comic books [31]. According to the personal experience and years of observations by the author, those who enjoy reading and have the habit of reading are never limited to a genre. Rather, they can enjoy the pleasure of reading with any books, anytime and anywhere.

\section{Conclusions}

Many people believe that only hard work pays off when it comes to language learning, so they force themselves into unsuitable or unpleasant ways of learning. As a matter of fact, language learning can be fun, with the right methods. There is no quick way of developing reading habits, and it takes time for such habits to bear fruit in learning achievements. However, the impact of learning habits on 
language learning outcomes is deep and profound and it is worth the efforts. Exposure to different theories and different knowledge domains does not only broaden the horizon but also boost the learning efficiency. Even though the mediating effect of deep knowledge principles is not statistically significant, the theoretical framework suggests relations among the variables $[12,13]$. A further cross-sectional or longitudinal research should be conducted to investigate the relationship between principles of deep knowledge and language learning.

\section{REFERENCES}

[1] I. N. Chiang. Can children and parents read happily ever after? An investigation of extensive reading in Taiwan, Unpublished doctoral thesis. Newcastle University. Newcastle-upon-Tyne. 2009.

[2] W. Elley. Acquiring literacy in a second language: The effect of book-based programs, Language Learning, Vol. 41, 375-411. 1991.

[3] W. Elley. Raising literacy levels in third world countries: A method that works, Language Education Associates, Culver City, California, 1998.

[4] S. Krashen. The power of reading: Insights from the research, Heinemann, Portsmouth, NH, 2004.

[5] B. Mason. The efficient use of literature in second language education: Free reading and listening to stories, In J. Bland \& C. Lütge (Eds.), Children's literature in second language education, Bloomsbury Academic, New York, 2013.

[6] T. Robb, M. Kano. Effective extensive reading outside the classroom: A large-scale experiment, Reading in a Foreign Language, Vol.25, No.2, 234-247, 2013.

[7] P. Yu. Habitual Domains: Freeing yourself from the limits on your life, Highwater Editions, Kansas, 1995.

[8] D. S. Guo, Y. T. Hiseh. An exploratory quantitative study of learning effect for habitual domain's seven self-perpetuating operators, Journal of Habitual Domains, Vol.2, No.1, 51-7, 2010.

[9] T. Y. Chang, Y. C. Wang, Y. C. Lo. Research in creative towel designs by applying habitual domain's innovation concept. An industry-academy cooperation case study of yungpeng, Journal of Habitual Domains, Vol.4, No.1, 23-42, 2012.

[10] L. Lin. Expanding and application of habitual domains with illustrations in solving vocational stresses and parent-children conflicts, Journal of Habitual Domains, Vol.4, No.1, 107-124, 2012.

[11] Y. R. Chen. A creative teaching in modern poetry with integration of habitual domain theory, Journal of Habitual Domains, Vol.4, No.1, 57-70, 2012.

[12] I. N. Chiang. Principles of deep knowledge and language learning, The proceedings of the $19^{\text {th }}$ annual conference of habitual domains, Habitual Domain Association, Taichung, Taiwan, 1-9, 2011.
[13] I. N. Chiang. The habitual domain, brain research and language learning, Journal of Habitual Domains, Vol.4, No.1, 43-56, 2012.

[14] M. Huang. Reading classic and expansion of habitual domain - take Hamlet as an example, Journal of Habitual Domains, Vol.1, No.1, 105-118, 1999.

[15] L. Lin. Habitual domains and the learning achievement: In the case of the Chinese courses in university, Journal of Habitual Domains, Vol.5, No.2, 65-84, 2013.

[16] S. Krashen. The input hypothesis: Issues and implications, Longman, London, 1985.

[17] S. Mahadeo. Input and achievement in an acquisition-poor environment: varying levels of L2 proficiency among pre-puberty Mauritian learners of English, Unpublished doctoral thesis, University of Durham, Durham, 2003.

[18] C. Burstall. French from eight, a national experiment, NFER, Slough, 1968.

[19] C. Burstall. French in the primary school: Attitudes and achievements, NFER, Slough, 1970.

[20] J. B. Carroll. Psychological and educational research into second language teaching to young children, In H. H. Stern (Ed.), Languages and young school child, Oxford University Press, London, 56-68, 1969.

[21] M. García Mayo. Age, length of exposure and grammaticality judgements in the acquisition of English as a foreign language, In M. García Mayo \& M. L. García Lecumberri (Eds.), Age and the acquisition of English as a foreign language, Multilingual Matters, Clevedon, 2003.

[22] F. Genesee. Learning through two languages: Studies of immersion and bilingual education, Newbury House, Cambridge, MA, 44-61, 1987.

[23] W. Lambert, G. Tucker. Bilingual Education of Children: The St. Lambert Experiment, Newbury House, Rowley, Mass., 1972.

[24] S. Lapkin, D. Hart, M. Swain. Early and middle French immersion programs: French language outcomes, The Canadian Modern Language Review, Vol.48, 11-40, 1991.

[25] N. Chomsky. Aspects of the theory of Syntax, MIT Press, Cambridge, Mass., 1965.

[26] S. Krashen. Principles and practices in second language acquisition, Pergamon Press, New York, 1982.

[27] P. Lightbown. What have we here? Some observations on the effect of instruction on L2 learning, In R. Phillipson, E. Kellerman, L. Selinker, M. Sharewood Smith, M. Swain. (Eds.) Foreign/second language pedagogy research, Multilingual Matters, Clevedon, Avon, 1991.

[28] N. Spada. The interaction between types of content and type of instruction: some effect on the L2 proficiency of adult learners, Studies in Second Language Acquisition, Vol.8, 181-99, 1986.

[29] R. Rigy. Audio-visual aids and techniques in managerial and supervisory learning. Hamial Hamiton, London, 1980.

[30] S. Krashen. The Goodman/Smith hypothesis, the input hypothesis, the comprehension hypothesis, and the (even stronger) case for free voluntary reading, online available 
from http://www.sdkrashen.com/content/articles/many_hypo thesis.pdf

[31] B. Mason, S. Krashen. Extensive reading in English as a foreign language, System, Vol.25, No.1, 91-102, 1997.

[32] B. Mason. The efficiency of self-selected reading and hearing stories on adult second language acquisition, In selected papers from the sixteenth international symposium on English teaching, English Teachers' Association ROC, Taipei, Taiwan, 630-633, November 9-11, 2007.

[33] B. Mason. Free voluntary reading and autonomy in second language acquisition: Improving TOEFL scores from reading alone, The International Journal of Foreign Language Teaching, Vol.2, No.1, 2-5, 2006.

[34] B. Mason. Impressive gains on the TOEIC after one year of comprehensible input, with no output or grammar study, Paper presented at the $19^{\text {th }}$ international conference at English Teachers' Association ROC, November, 12-14, 1997,2010

[35] I. N. Chiang. Extra-curricular input via extensive reading at the tertiary level, The sixth conference on college English, National Chengchi University, 2012

[36] J. Yamashita. Reading attitudes in L1 and L2, and their influence on L2extensive reading, Reading in a Foreign Language, Vol.16, 1-19, 2004.

[37] R. Waring, M. Takakei. At what rate do learners learn and retain new vocabulary from reading a graded reader? Reading in a Foreign Language, Vol.15, No.2, 130-163, 2003.
[38] C. Kirchhoff. L2 extensive reading and flow: Clarifying the relationship, Reading in a Foreign Language, Vol.25, No.2, 192-212, 2013.

[39] K. Kitao, M. Yamamoto, S. K. Kitao, H. Shimatani. Independent reading in English - use of graded readers in the library English as a second language corner, Reading in a Foreign Language, Vol.6, No.2, 383-395, 1990.

[40] P. L. Yu. Working knowledge mining by principles for deep knowledge, International Journal of Information Technology \& Decision Making, Vol.5, No.4, 729-738, 2006.

[41] I. N. Chiang. A new interpretation of English reading activities: The implementation of the principles of deep knowledge, International Journal of Language and Linguistics, Vol.2, No.4, 152-161, 2015.

[42] P. L. Yu. Habitual domains and forming winning strategies, NCTU Press, Hsin-Chu, Taiwan, 2002.

[43] P. L. Yu. Habitual Domains - The under-discussed human software, China Times Publishing Co., Taipei, 1998.

[44] K. J. Preacher, A. F. Hayes. SPSS and SAS procedures for estimating indirect effects in simple mediation models, Behavior Research Methods, Instruments, and Computers, Vol.36, 717-731, 2004

[45] M. Strobel, A. Tumasjan, M. Spörrle. Be yourself, believe in yourself, and be happy: Self-efficacy as a mediator between personality factors and subjective well-being, Scandinavian Journal of Psychology, Vol.52, 43-48, 2011. 